\title{
Mobility Trends and their effect on Traffic Safety During the Covid-19 Pandemic: Case Study Republic of Croatia
}

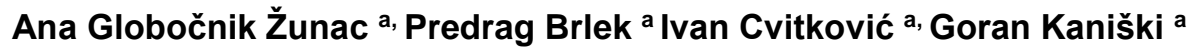 \\ a University North, Department for logistics and sustainable mobility, Trg Žarka Dolinara 1, 48000 Koprivnica, Croatia
}

\begin{tabular}{|c|c|}
\hline ARTICLE INFO & A B S T R A C T \\
\hline $\begin{array}{l}\text { DOI: } 10.31075 / P I S .67 .04 .03 \\
\text { Professional paper } \\
\text { Received: } 15 / 11 / 2021 \\
\text { Accepted:20/11/2021 } \\
\text { Corresponding author: } \\
\text { pbrlek@unin.hr } \\
\text { Keywords: } \\
\text { Sustainable Mobility } \\
\text { Traffic Safety } \\
\text { COVID-19 } \\
\text { This article has been presented at the 8th } \\
\text { International Conference } \\
\text { "Towards a Humane City" } \\
112 \text { November 2021, N. Sad, Serbia }\end{array}$ & $\begin{array}{l}\text { Safety analysis focuses on how traffic safety can change while mobility analysis } \\
\text { is used to determine how people change travel behavior. The integration of } \\
\text { mobility, safety and behavioral data related to COVID-19 can provide valuable } \\
\text { insights to decision makers. Wide availability of mobile sensors has given us the } \\
\text { opportunity to be able to assess changes in the performance and mobility of } \\
\text { transport systems in, almost real time. The researchers also measured the } \\
\text { impact of COVID-19 on human mobility using public mobile location data } \\
\text { available from many companies such as Google and Apple, which is very useful } \\
\text { for changing human mobility. The platforms produce aggregated metrics of daily } \\
\text { mobility, including the purpose of travel, the mode of travel, and imputations of } \\
\text { social demographics. Based on a comprehensive data set of people who } \\
\text { participated in the collected accident data and mobile device data, we record } \\
\text { the impact of COVID-19 on traffic safety. The paper systematically and } \\
\text { statistically approaches the assessment of road safety in Croatia during the } \\
\text { COVID-19 pandemic. }\end{array}$ \\
\hline
\end{tabular}

\section{Introduction}

on March 11, 2020, the World Health Organization declared a global pandemic because of a new infectious coronavirus, also known as COVID-19. All countries were affected by the coronavirus epidemic. In response, national governments have implemented suppression measures focused on reducing people's mobility and social interactions. Strict restrictions and policies have been introduced in various countries to limit the spread of COVID-19, including quarantines, job and education restrictions, reduced shopping and physical activities, and ban social gatherings.

All the measures adopted to protect human health were actually aimed at preventing the movement of people and their contact. To limit the occurrence of the virus and the likely casualties, most governments around the world have conducted quarantines. Due to the relatively limited space, public transport stations and cars are considered to be the area with the highest risk of COVID-19 spread.
Reduced mobility also indirectly affected the reduction in traffic volume. Prohibitions on leaving the place of residence and reduced public transport load, have led to a smaller number of personal vehicles and public transport vehicles on the roads. Following the available data and traffic analyzes, the question arises whether all this together led to a reduction in the number of traffic accidents and injuries in traffic in the year 2020. This article analyzes in detail the traffic safety situation during the COVID-19 pandemic in the Republic of Croatia. This study looks at traffic safety according to the records of traffic accidents with injured and fatalities in the time before and during the COVID-19 pandemic. This is a preparatory study and when more data becomes available the report will be updated with better estimates.

\section{Methodology and resources}

Community mobility reports that is released by Google show movement trends by region, across different categories of places. For each category in a region, reports show the changes in two different ways. Compares mobility for the report date to the baseline day. 
Calculated for the report date and reported as a positive or negative percentage. Using anonymous data provided by apps like Google Map, the company has created a regularly updated dataset that shows how people's movements changed during a pandemic. Since road transport and air transport were two key dimensions for the spread of COVID-19, one of the restrictions imposed was the restriction of personal mobility.

This Google data set measures the number of visitors to certain categories of places on a daily basis and compares this change to the starting day before the outbreak. Baseline days represent the normal value for that day of the week, which is given as the average over five weeks from January 3 to February 6, 2020.

Similar to Google data, Apple released a series of mobility data related to the COVID-19 pandemic. Data are collected from requests for instructions in Apple Maps and are provided nationwide, as well as for the selection of major cities around the world. Apple has released time series data for countries and cities for each of the two modes of movement: driving and walking.

\subsection{Mobility Trends in Croatia}

The chart of Figure 1. shows the relative volume of requests for driving and walking in Republic of Croatia, compared to the base volume of January 13, 2020. In a part of the country, on March 14, 2020, preventive measures were introduced and on March 19, 2020, the implementation of "lockdown" measures, to close most stores and cancelling public events across the country, began. On March 21, 2020, the National Headquarters issued a decision to strictly limit detention on the streets, squares and other public places, as well as a decision to suspend public transport in order to prevent an increase in the number of infected people. Intercity lines for trains and buses are also being cut off.

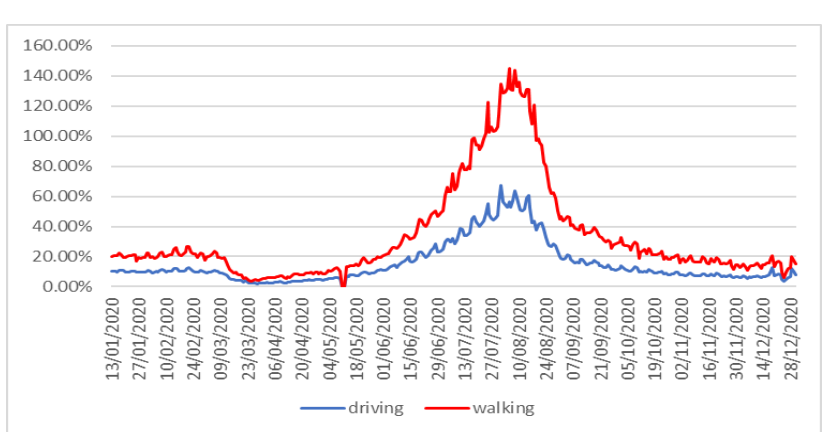

Figure 1. Mobility Trends Report from Croatia

Source: Apple reports on trends of mobility. [Online]. Available at: https://covid19.apple.com/mobility [Accessed June 27, 2021].

The graph shows the largest decline in mobility on March 23, 2020, and the reason is the ban on leaving the place of residence or permanent residence.
By the decision of the National Headquarters on April 27,2020 , the first phase of relaxation pandemic protection measures in order to partially start the economy came into force. This enables the work of all business entities that perform the activity of trade, except those that perform trade activities, except for those who operate shopping centers. The third phase of relaxation epidemiological measures began on May 11,2020 , so schools were opened for some students, and after almost two months, shopping malls, caffes and restaurants began to operate. This establishes a long-distance road, rail and domestic air transport of passengers, as well as open bus and train stations for long-distance traffic.

\subsection{Traffic safety analysis}

In Croatia, The Ministry of the Interior takes care of the road traffic safety. In order to make this part of the work as successful as possible, the condition and changes in road safety are systematically monitored. The results of this work are statistical information that provides a more detailed and complete picture of the state of road safety in the Republic of Croatia and all risk factors that threaten it. Following the available data and traffic analysis, the question arises whether all this together led to a reduction in the number of traffic accidents and injuries in traffic in the 2020. In Table 1. compared are the number of traffic accidents before and during the COVID-19 pandemic.

Table 1. Traffic accidents by months with fatalities and injured persons [4]

\begin{tabular}{|c|c|c|c|c|c|c|}
\hline \multirow{2}{*}{ Month } & \multicolumn{5}{|c|}{ Traffic accidents } \\
\cline { 2 - 7 } & \multicolumn{2}{|c|}{ Total } & \multicolumn{2}{l|}{ With fatalities } & \multicolumn{2}{l|}{ With injured persons } \\
\cline { 2 - 7 } & $\mathbf{2 0 1 9}$ & $\mathbf{2 0 2 0}$ & $\mathbf{2 0 1 9}$ & $\mathbf{2 0 2 0}$ & $\mathbf{2 0 1 9}$ & $\mathbf{2 0 2 0}$ \\
\hline January & 2.18 & 2.191 & 20 & 21 & 536 & 636 \\
\hline February & 2.092 & 1.893 & 14 & 18 & 556 & 521 \\
\hline March & 2.437 & 1.621 & 12 & 11 & 720 & 402 \\
\hline April & 2.417 & 1.265 & 22 & 16 & 723 & 349 \\
\hline May & 2.553 & 1.972 & 24 & 16 & 753 & 585 \\
\hline June & 2.966 & 2.522 & 28 & 24 & 976 & 773 \\
\hline July & 3.146 & 2.824 & 24 & 33 & 997 & 939 \\
\hline August & 3.08 & 2.878 & 26 & 19 & 1.042 & 918 \\
\hline September & 2.807 & 2.47 & 27 & 18 & 903 & 775 \\
\hline October & 2.746 & 2.501 & 31 & 13 & 870 & 639 \\
\hline November & 2.371 & 1.969 & 16 & 13 & 667 & 490 \\
\hline December & 2.572 & 1.968 & 35 & 12 & 673 & 469 \\
\hline Total & 31.367 & 26.074 & 279 & 214 & 9.416 & 7.496 \\
\hline
\end{tabular}

Source: Bulletin about road safety 2019, 2020, Republic of Croatia, Ministry of the Interior 
The data show that the lockout set by the Croatian government on March 21, 2020, as a measure to drastically reduce the spread of COVID-19 disease, has led to a significant reduction in traffic accidents. Although the number of accidents can vary from year to year and even from season to season, the huge difference in the number that occurred during 2020 and the equivalent period in 2019 , as well as between the periods before and during isolation, can mainly be attributed to lockdown. The probability of a traffic accident is higher if there are more vehicles on the roads.

In a year that will be remembered for the pandemic, the number of deaths decreased by 65 people, i.e. from 279 in 2019. to 214 in 2020., which is a 23.30 percent lower number of deaths. It was recorded and reduce the number of road accidents, and with 31367 in 2019. to around 26074 in 2020., which is 5293 fewer traffic accidents or 16.87 percent lower number of traffic accidents. Last year, there were about 20.39 percent fewer injured, or 9416 compared to 7496 during 2019., which is 1920 fewer accidents with injured people, according to police statistics.

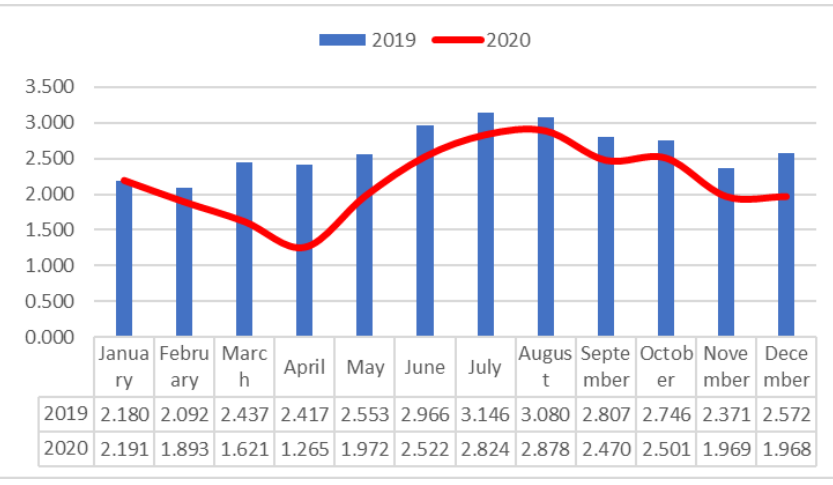

Figure 1. Comparison of the number of traffic accidents in 2019 and 2020

Source: Bulletin about road safety 2019, 2020, Republic of Croatia, Ministry of the Interior

The results suggest that during April when the strictest measures were in place for the entire month, traffic accidents dropped approximately by 47.66 percent, deaths declined by 43 percent and injuries declined by 64 percent compared to April of 2019.

The total number of registered road vehicles in the Republic of Croatia amounted to 2312280 in 2020, which was 1.6 percent more than in 2019. The total number of registered passenger cars amounted to 1746285 in 2020, which was an increase of 1.2 percent compared to 2019. The number of first registrations of road vehicles amounted to 132572, which was a significant decrease of 31.8 percent compared to 2019. The decrease in first registrations was recorded for all types of vehicles.
The circumstances brought about by the spread of the COVID-19 disease have directly influenced the decrease in the number of first registrations of road vehicles. The number of first registrations of passenger cars amounted to 95577 in 2020., which was a decrease of 35.9 percent compared to 2019. The decrease was caused by the reduction in the number of first registrations of used cars (27.6 percent) and new vehicles (49.9 percent).

\section{Conclusion}

In order to raise the road safety situation to a higher level, society must invest significantly more efforts in improving road infrastructure and developing a traffic culture. A large part of this effort belongs to the Ministry of the Interior, i.e. the traffic police, whose activities influence the increase of traffic discipline of all participants. The development of traffic accidents after a period of isolation should be studied.

The unexpected benefits of the crisis caused by the COVID-19 pandemic are likely to persist only if mobility restrictions are maintained or if new public policies are designed and implemented to allow for a gradual change in mobility patterns. The rapid growth in the share of bicycles and e-scooters has created new challenges for policy makers and regulators and exacerbated some pre-existing fears. Areas of concern include safety, not just the consequence of potential conflict with other means, consumer protection and external influences, especially the overcrowding of public spaces with an excessive number of sometimes neglected bicycles or scooters.

Although traffic has increased in recent months with some return to work and to school, reluctance to use public transport and parking, and a large number of delivery vehicles, many of the risk behaviors continue. The problem is further exacerbated by a significant increase in the number of pedestrians and cyclists on the roads. It has become clearer than ever that roads do not belong only to vehicles, but are common areas for cars, pedestrians, cyclists, scooters and other modes of transport.

Due to the limited data and information available, no more advanced methods have been used in this study, but they will be included in future research. If sufficient quality data is available, a more detailed picture of the impact of COVID-19 and quarantine on road and transport system safety could be produced, but this could be explored in future studies. 


\section{References}

[1] Musselwhit, C., Avineri, E., Susilo, Y.: Editorial JTH 16-the Coronavirus Disease COVID-19 and implications for transport and health. J Transport Health. 2020;16:100853.

[2] $\mathrm{Wu}$, JT., Leun,g K., Leung, GM.: Nowcasting and forecasting the potential domestic and international spread of the 2019-nCoV outbreak originating in Wuhan, China: a modelling study. The Lancet. 2020;395(10225):689-97.

[3] Brlek, P., Cvitković, I., Martinčević, I. \& Kos, G.: Economic Aspects of the COVID-19 pandemic on external transport costs. 61st International Scientific Conference on Economic and Social Development - "Corporate social responsibility in the context of the development of entrepreneurship and small businesses", p. 7382, Varazdin, University North, 2020.

[4] Apple reports on trends of mobility. [Online]. Available at: https://covid19.apple.com/mobility [Accessed June 27, 2021].

[5] Bulletin about road safety 2019, 2020, Republic of Croatia, Ministry of the Interior

[6] Central Bureau of Statistics of the Republic of Croatia. Registered road vehicles and road traffic accidents in 2018.

[7] Keček, D., Brlek, P. \& Buntak, K.: Economic effects of transport sectors on Croatian economy: an input-output approach. Economic Research, online, p. 1-16, 2021. 